nature

chemical biology

\section{Back to school}

A $s$ students initiate the annual ritual of stocking up on textbooks for the fall term, we thought it might be an appropriate time to consider what it means to educate the next generation of chemical biologists. Several important educational questions confront scientists who work at the interface of chemistry and biology. How must our traditional teaching models evolve to support interdisciplinary education? How do we make our classrooms more accurately reflect how scientific inquiry proceeds at the chemistry-biology interface? The answers to these questions are critical for the future of chemical biology.

Following on the recent expansion of research programs at the chemistry-biology interface, chemical biology educational initiatives have received increasing attention in chemistry and biology departments at universities and colleges worldwide. Curricular changes typically have appeared first in graduate-level educational programs. As an initial step, chemical biology faculty members have created new courses to provide their graduate students with the chemical and biological knowledge necessary to excel in the research laboratory. Many forward-thinking universities have now created interdepartmental graduate training programs in chemical biology, which include chemistry, biology, engineering and medical school departments. Although these are steps in a positive direction, there still remain significant challenges to chemical biology education at the graduate level.

One challenge to developing broad-based educational initiatives in chemical biology is the traditional departmental structure of universities. Although departments may be useful administrative units, they create unintended barriers to educational innovation in emerging fields. For example, in most current chemical biology programs, students select from existing courses from chemistry and biology departments. To bring chemical biology training more in line with the interdisciplinary nature of the field, universities will need to solve the difficult issues of allocating financial resources, tenure-track faculty lines and teaching loads, and incentives to spur innovation across departmental lines. Team-taught courses involving faculty from multiple departments provide one approach to integrated chemical biology teaching.

Cultural differences between chemistry and biology departments also create challenges for chemical biology educational programs. For example, in chemistry departments, graduate students traditionally join a research group near the end of their first term. In contrast, biology students usually participate in a series of "rotations" in different research laboratories before joining a group near the end of their first year. Many chemical biology programs have adopted limited rotation systems for graduate student placement. However, no clearly successful approach has emerged. This may be due to the questions that arise by attempting to change wellestablished models. For example, will adding rotations increase the time required to obtain a $\mathrm{PhD}$ ? Is there sufficient funding support to initiate and sustain such training programs?

A third challenge for chemical biology education is to guarantee that students are well-prepared to enter interdisciplinary graduate programs. Although most chemistry or biology students complete their undergraduate degrees proficient in their major field, few are fully conversant in both chemistry and biology. The significant coursework required for undergraduate degrees in chemistry or biology leaves little time for additional classes or majors. However, even if completion of these courses were possible, focused disciplinary coursework falls far short of an integrated approach that would reflect how chemical biology operates.

Fortunately, chemical biologists are already addressing these educational challenges. In this issue of Nature Chemical Biology, we include a Commentary from Hilary Arnold Godwin that outlines how hypothesis-driven approaches can be used to teach fundamental concepts from both chemistry and biology. Recent statistics from the University of California at Berkeley offer another promising example. In 2003, the chemistry instituted a chemical biology undergraduate major. By 2004 the number of chemistry department majors had increased by more than $50 \%$. This dramatic rise was reflected in the number of chemical biology students, whereas enrollment in traditional majors remained stable. These statistics highlight the possibility that chemical biology educational initiatives may attract new science students, rather than depleting traditional chemistry or biology majors.

Recently, much has been written about the future of chemistry as a discipline. News reports highlight the closing of chemistry departments in the United Kingdom (Nature 432, 543, 2004), and recent statistics (Chem. Eng. News, 7 February 2005, 3846) point toward a general decline in the numbers of chemistry degrees granted in the United States. However, in our view, chemical biology might serve as a rejuvenating force for chemistry education and research.

We are interested in hearing your views on chemical biology education. Please submit your correspondence at http://www.nature. com/naturechemicalbiology or e-mail us at chembio@boston. nature.com. 